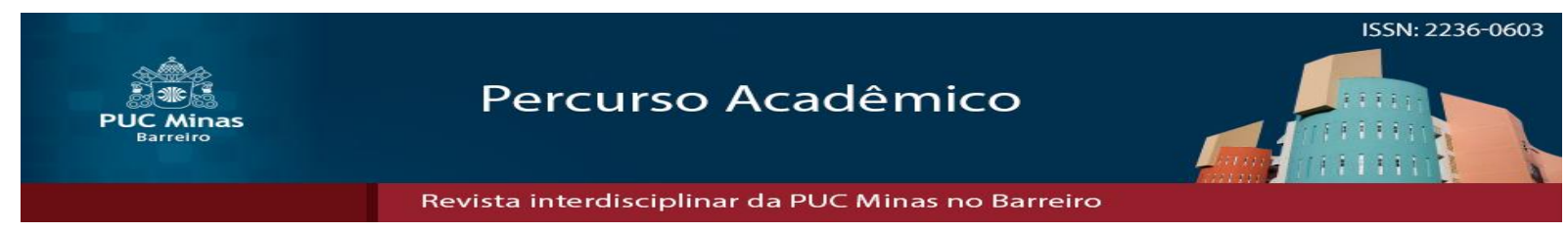

\title{
Estupro de vulnerável: a relevância da palavra da vítima para fins de prova e condenação.
}

\author{
Rape of vulnerable: the relevance of the victim's word for the purpose of proof and \\ conviction.
}

Giovana Virginia Maria dos Reis Silva ${ }^{1}$

Marília Bachi Comerlato Paschoalick ${ }^{2}$

\begin{abstract}
RESUMO
O presente artigo tem como objetivo analisar e discorrer acerca das fragilidades advindas da previsão expressa no artigo 217-A, caput, do Código Penal, qual seja, o estupro de vulnerável, em especial a relevância da palavra da vítima para fins de fundamentar a sentença penal condenatória e a fragilidade dessa prova, que pode acarretar em uma injusta condenação. Isso porque ao atribuir um relevante valor probatório à palavra da vítima, como único meio de prova, sem se atentar as fragilidades e influências externas que a mesma pode estar revestida, ou seja, não considerar eventuais contextos em que a criança está inserida, abre-se brechas que podem incorrer em possíveis erros no processo. A título de exemplo, não raras vezes, ela por estar investida de falsas memórias em razão de alienação parental ou até mesmo em decorrência de erro no laudo psicológico, situações essas que serão abordadas no decorrer do trabalho. Sendo assim, necessária uma adequação no ordenamento jurídico penal brasileiro, em consonância com a Resolução 299/19, exigindo a capacitação adequada de profissionais da psicologia, conforme a realidade em que se vive e as transformações no entendimento e desenvolvimento das crianças e adolescentes, de forma a proteger o vulnerável, pois um processo criminal é desgastante e pode deixar sequelas psíquicas a mesma. Além de oferecer uma efetiva prestação jurisdicional à vítima e ao acusado, para que assim possa ser evitada a condenação de um inocente e suas inevitáveis consequências.
\end{abstract}

Palavras-chave: Estupro. Estupro de vulnerável. Presunção absoluta. Palavra da vítima. Injusta condenação.

\begin{abstract}
This article aims to analyze and discuss the weaknesses resulting from the provision expressed in Article 217-A, caput, of the Penal Code, that is, the rape of vulnerable, especially the relevance of the victim's word for the purpose of substantiating the sentence and the fragility of this evidence, which may lead to an unjust conviction. This is because by attributing a relevant probative value to the victim's word, as the only means of proof, without looking at the weaknesses and external influences that it may be coated with, that is, not considering any contexts in which the child is inserted, gaps are opened that may incur possible errors in the process. By way of example, often, she is invested with false memories due to parental alienation or even due to error in the psychological report, situations that will be addressed during the work. Thus, an adequacy in the Brazilian criminal legal system is necessary, in line with Resolution 299/19, requiring the adequate training of psychology professionals, according to the reality in which one lives and the transformations in the understanding and development of children and
\end{abstract}

Artigo recebido em 28 de julho de 2020 e aprovado em 24 de novembro de 2020.

${ }^{1}$ Graduanda do Curso de Direito do Centro Universitário da Grande Dourados (UNIGRAN), Mato Grosso do Sul, Brasil. E-mail: giovana.reis784@gmail.com

${ }^{2}$ Mestrado em Direito da Sociedade da Informação pelas Faculdades Metropolitanas Unidas - FMU, Bacharel em Direito pelo (UNIGRAN). Atualmente é docente do Curso de Direito do UNIGRAN e Advogada, Brasil. E-mail: marilia.comerlato@unigran.br 
adolescents, in order to protect the vulnerable, because a criminal process is exhausting and can leave psychic sequelae the same. In addition to offering an effective judicial benefit to the victim and the accused, so that the conviction of an innocent person and its inevitable consequences can be avoided.

Keywords: Rape. Rape of vulnerable. Absolute presumption. Victim's word. Unfair condemnation.

\section{INTRODUÇÃO}

O crime de estupro existe desde os primórdios, sendo considerado intolerável e repugnante perante a sociedade e o ordenamento jurídico. É um crime bárbaro e aterrorizante, que abrange todos os gêneros, idades e etnias. Porém, quando o assunto envolve crianças e adolescentes vítimas de estupro, a revolta social é muito maior, haja vista serem seres de pouca idade, com pequeno ou até inexistente conhecimento sexual.

Infelizmente, o número de ocorrências envolvendo menores tem aumentado drasticamente nos últimos anos, o que fez surgir uma nova configuração legal, um tipo penal autônomo, chamado de "Estupro de Vulnerável", objeto de discussão do presente artigo. Este, encontra-se instituído na Lei 12.015/09 - Lei dos Crimes contra a dignidade sexual, prevista no caput do art. 217-A do Código Penal, Capítulo II do Título VI.

Dentre as mudanças decorrentes da lei, está a rigidez na aplicabilidade, o aumento da pena, fusão de alguns dispositivos e a presunção absoluta com relação à vulnerabilidade, o que será, inclusive, discutido mais à frente.

Como é sabido, os pais têm grande influência sobre seus filhos, seja em relação ao seu comportamento, na construção de seu caráter ou na forma de pensar. Aqui não seria diferente. Polêmicas envolvendo genitores que influenciam seu próprio filho a pensar e fazer acusações de conotação sexual contra o outro genitor, algo até então desconhecido no seu pequeno mundo de brincadeiras e inocências, dá-se origem a uma série de consequências irreversíveis. Onde, talvez, nem seja identificado pelo próprio psicólogo responsável pela entrevista e futura formação do laudo.

Em crimes como este, geralmente ocorre na ausência de testemunhas e nem sempre deixa vestígios, sendo assim considerado clandestino/oculto. O que se tem é apenas a palavra da criança, na qual abrem-se brechas para uma condenação injusta, baseada em um depoimento que pode estar alienado por um dos pais, seja por vingança ou descontentamento com o acusado. Ou ainda, revestida de falsas memórias, o que também não é culpa da criança, mas deve ser observado. 
Ainda, será abordado o desafio que os profissionais da área da psicologia enfrentam ao avaliar a criança, bem como, o despreparo profissional de uns e o envolvimento emocional com o menor, que pode interferir na oitiva desta $\mathrm{e}$ consequentemente na condenação de um inocente.

Assim, o presente trabalho tem por objetivo demonstrar o quão frágil é a prova baseada na oitiva da criança, tendo em vista os vários elementos externos que podem interferir na busca pela verdade real. Pois, sendo este um crime considerado tão bárbaro e de grande repercussão social, não deve haver margens para erros, e muito menos para o encarceramento de inocentes e suas inevitáveis consequências.

\section{CONCEITUAÇÃO DE ESTUPRO}

O crime de estupro está tipificado no art. 213 do Código Penal, onde vislumbra a seguinte redação "constranger alguém, mediante violência ou grave ameaça, a ter conjunção carnal ou a praticar ou permitir que com ele se pratique outro ato libidinoso. Pena - reclusão, de 6 (seis) a 10 (dez) anos”.

Segundo Greco (2017), é considerado um crime de natureza hedionda e de elevado potencial ofensivo; podendo ser o sujeito ativo do delito pessoa de qualquer sexo com dolo, ou seja, que possua a intenção (animus) de ter conjunção carnal ou outro ato libidinoso com outrem, sem que este consinta. Não admite-se a figura culposa, porém admite-se a tentativa.

Capez (2017) esclarece que "com o advento da Lei 12.015/2009, a mulher poderá ser coautora e partícipe do crime de estupro como também autora, em virtude de o tipo penal, a partir de agora, abranger os atos libidinosos diversos da conjunção carnal”. (CAPEZ, 2017, p. 105). Dessa maneira, o crime de estupro passou a abranger a garantia da dignidade sexual de todo ser humano, englobando não somente a conjunção carnal, mas também outras formas de violação sexual. Assim,

O presente tipo penal, a partir da redação determinada pela Lei $n$. 12.015/2009, insere-se na finalidade abrangente de garantir a todo ser humano, que tenha capacidade de autodeterminar-se sexualmente, que o faça com liberdade de escolha e vontade consciente, pretende-se, em outros termos, assegurar que a atividade sexual humana seja realizada livremente por todos. (BITENCOURT, 2017, p. 46). 
Para Masson (2016), o dispositivo em análise exige a discordância da vítima acerca do ato sexual, seja antes ou no decorrer do ato sexual. Isso significa que se no decorrer do ato sexual a vítima passar a discordar expressamente e o agente continuar insistindo no ato, usando de violência ou grave ameaça, estará caracterizado o crime de estupro.

Com relação a palavra da vítima, esta tem valor probatório relativo, ou seja, será aceita com reservas e em confronto com outras provas, ante a possibilidade de perjúrio e a injusta acusação de um inocente como autor do crime. Nesse sentido, entende - se que

\begin{abstract}
Nos delitos contra os costumes, a palavra da ofendida avulta em importância, principalmente quando se trata de pessoa recatada, de bons costumes, de vida anterior honesta e ilibada, recatada, e acima de suspeitas. Nessas condições, é muito evidente que suas declarações, apontando o autor do crime que lhe vitimou, assumem caráter extraordinário, frente às demais provas. Não seria razoável e nem é comum que a pessoa com essas qualidades viesse a juízo cometer perjúrio, acusando um inocente de lhe haver constrangido à conjunção carnal ou a ato libidinoso outro qualquer. Por isso, sua palavra, enquanto não desacreditada por outros meios de prova, digamos, vale como bom elemento de convicção. (ROCHA, 1999, p.355).
\end{abstract}

Portanto, em apreciação as mudanças no instituto, verifica-se a ampliação em sua aplicabilidade ao incluir os atos libidinosos como forma de estupro, bem como ao dispor sobres os sujeitos ativos e passivos do delito, onde agora abrange de forma igualitária todo ser humano, respeitando a dignidade sexual de cada indivíduo passível de sofrer violação.

Com relação ao estupro envolvendo menores, foco do presente estudo, não foi diferente, o legislador também trouxe alterações de grande relevância e discussão na égide jurídica, como será demonstrado no decorrer do artigo.

\title{
3 ESTUPRO DE VULNERÁVEL
}

O crime estupro de vulnerável deixou de ser uma espécie do crime de estupro e passou a ter sua própria redação, prevista no art. 217-A do Código Penal, possuindo o seguinte texto:

Art. 217-A. Ter conjunção carnal ou praticar outro ato libidinoso com menor de 14 (catorze) anos:

Pena - reclusão, de 8 (oito) a 15 (quinze) anos.

$\S 1^{\circ}$ Incorre na mesma pena quem pratica as ações descritas no caput com alguém que, por enfermidade ou deficiência mental, não tem o necessário discernimento para a prática do ato, ou que, por qualquer outra causa, não pode oferecer resistência. 


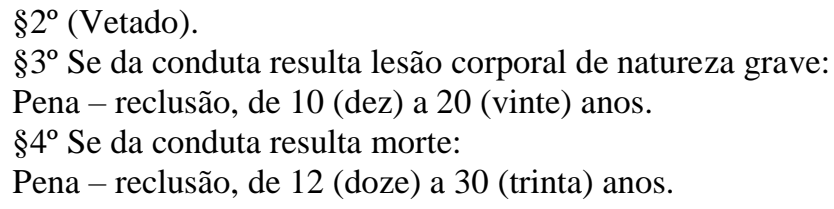

Segundo Masson (2016), é um crime hediondo, isto é, de maior reprovabilidade e potencial ofensivo, haja vista tratar-se de crime sexual contra crianças. O objeto material do crime é a pessoa vulnerável, independente do sexo e do consentimento da vítima, podendo ocorrer apenas mediante dolo, ou seja, não admite-se a forma culposa.

A palavra vulnerável emana da língua latina "vulnera bílis", que denota ser uma pessoa suscetível de ser ferido, frágil e incapaz de algum ato. Demonstra a fragilidade ou incapacidade de uma pessoa a depender de circunstâncias.

O objetivo do legislador ao criar esse novo tipo penal autônomo, era considerar a "proteção especial prevista na Constituição Federal e na Convenção da Organização das Nações Unidas sobre os Direitos da Criança, ratificada pelo Brasil", considerando não haver, nessa hipótese a admissão de compatibilidade entre o desenvolvimento sexual e o início da prática sexual. (LEGISLAÇÃO INFORMATIZADA, 2009).

O que o diferencia do estupro a qual se refere o art. 213 do Código penal é a condição de vulnerabilidade, pois a vítima é considerada mais frágil. Este é o entendimento de Masson (2016), no sentido de que

\footnotetext{
Existem atualmente dois crimes diversos, dependendo do perfil subjetivo do ofendido. Se a vítima é pessoa vulnerável, aplica-se o art. 217-A, ao passo que nas demais hipóteses incide o art. 213, ambos do Código Penal. Além disso, o estupro de vulnerável é crime mais grave, justificando-se a maior reprovabilidade na covardia do agente, na fragilidade da vítima e na amplitude dos efeitos negativos causados à pessoa de pouca idade, portadora de enfermidade ou deficiência mental ou sem possibilidade de resistir ao ato sexual. (MASSON, 2016, p. 59).
}

Mesmo que o menor de 14 anos tenha relações sexuais de livre e espontânea vontade, tenha um relacionamento com o agente ou até mesmo já tenha tido relações sexuais anteriormente, tudo isso é irrelevante quando se trata de estupro de vulnerável, pois a lei é clara ao dizer que o crime independe de consentimento. A súmula 593 do STJ trata exatamente disso, entendendo que

O crime de estupro de vulnerável configura com a conjunção carnal ou a prática de ato libidinoso com menor de 14 anos, sendo irrelevante o eventual consentimento da vítima para a prática do ato, experiência sexual anterior ou existência de relacionamento amoroso com o agente. 
Masson (2016) afirma que o núcleo desse tipo penal é dividido em duas condutas diversas, a primeira é no ato de ter conjunção carnal, podendo ser total ou parcial, em que é imprescindível a relação entre o agente e vítima de forma heterossexual. Enquanto a segunda é a prática de ato libidinoso, que não exige uma relação heterossexual.

A respeito da definição de atos libidinoso, Capez (2013), entende como

Ato libidinoso é todo coito anormal, os quais constituíam o crime de atentado violento ao pudor (antigo artigo 217 do $\mathrm{CP}$ ), asseverando que todo ato destinado a satisfazer a lascívia e o apetite sexual, inclusive o beijo lascivo, são considerados atos libidinosos, podendo se manifestar até mesmo sem o contato da genitália. (CAPEZ, 2013, p. 26).

O sujeito ativo do fato típico descrito na lei pode ser qualquer pessoa, na qual segundo Bitencourt (2017) abarca homem, mulher ou transgênero, seja em coautoria ou participação. No entanto, o sujeito passivo é determinado pelo estado de vulnerabilidade, independente do sexo, sendo o menor de 14 anos, enfermo ou doente mental, sem discernimento para a prática do ato, ou pessoa com incapacidade de resistência.

Ante o exposto, fica claro que a vulnerabilidade no crime de estupro de vulnerável é presumidamente absoluta, levando em consideração a idade do indivíduo e seu atual estado biológico. O que leva a uma maior rigidez do tipo penal e a não flexibilização aplicada a casos concretos.

\section{DA VULNERABILIDADE ABSOLUTA}

Segundo Nucci (2010), ao redigir o art. 217-A, o legislador definiu o estado de vulnerabilidade de maneira absoluta, visando proteger aqueles que pela lei, não possuem discernimento e capacidade para consentir nos atos sexuais. Foi usado como fator de equiparação a faixa etária, - onde iguala todos os menores de 14 anos -, e a condição de enfermidade e doença mental.

Com relação aos motivos que levaram ao surgimento da Lei $12.015 / 09$, no que tange o estupro de crianças e adolescentes, expõe-se que:

Trata-se de reivindicação antiga dos grupos e entidades que lidam com a temática, sob o argumento de que a norma penal, além de desatualizada quanto a termos e enfoques, não atende a situações reais de violação da liberdade sexual do indivíduo e do desenvolvimento de sua sexualidade, em 
especial quanto tais crimes são dirigidos contra crianças e adolescentes, resultando, nesse caso, no descumprimento do mandamento constitucional contido no art. $227, \S 4^{\circ}$, de que "a lei punirá severamente o abuso, a violência e a exploração sexual da criança e do adolescente". (LEGISLAÇÃO INFORMATIZADA, 2009).

Anteriormente a referida lei, era muito debatido nos Tribunais sobre a relativização da presunção de violência, prevista no revogado art. 224, alínea "a" do Código Penal, onde uns entendiam ser absoluta e outros, relativa.

Sobre a temática, Bitencourt (2017) defende que há diferença entre a presunção relativa e absoluta de vulnerabilidade. Entendendo ser absoluta aquela onde não se questiona esse aspecto, é incontestável; enquanto a presunção relativa a vítima pode ou não ser vulnerável, devendo examinar o caso individualmente. Devendo assim, ser comprovada.

Com a hodierna redação do art. 217-A do Código Penal, para Greco (2013) colocou um ponto final na discussão, não podendo os Tribunais entenderem de outra forma, em se tratando de vítima menor de 14 anos.

Seguindo o entendimento da nova redação legal, sobre o tema da presunção absoluta de vulnerabilidade, vejamos a seguinte decisão:

EMENTA AGRAVO REGIMENTAL NO HABEAS CORPUS. ESTUPRO
DE VULNERÁVEL. REEXAME DO CONJUNTO FÁTICO-
PROBATÓRIO EM SEDE DE RECURSO ESPECIAL. INOCORRÊNCIA.
PRESUNÇÃO DE VIOLEENCIA. CARÁTER ABSOLUTO. 1. A mera
relevância jurídica dos elementos de prova utilizados na apreciação dos fatos
pelo magistrado de primeiro grau não implica reexame do acervo fático-
probatório, porquanto meramente jurídica a questão de fundo. Precedentes. 2.
"A jurisprudência desta Corte Suprema perfilha entendimento de ser absoluta
a presunção de violência nos casos de crime de estupro praticado contra
menor de catorze anos (estupro de vulnerável), independentemente da
conduta ter sido praticada, antes ou depois, da vigência da Lei 12.015/2009”
(ARE 940.701-AgR/SP, Rel. Min. Gilmar Mendes, 2 $2^{\mathrm{a}}$ Turma, Dje
12.4.2016); 3. Agravo regimental conhecido e não provido. (HC 130.297--
AgR/PI, Rel. Min. Rosa Weber, Primeira Turma, Julgado em 15/10/2018).
(BRASIL, 2018).

No entanto, a discussão acerca do assunto ainda se estende, dividindo opiniões entre os juristas mais renomados do país. Franco (2011) afirma que o ideal seria distinguir as crianças e os adolescentes, assim entendidos pelo ECA - Estatuto da Criança e adolescente, quando se tratar de estupro de vulnerável, isto é, relativizando a vulnerabilidade dos adolescentes. Pois, no art. $2^{\circ}$ do referido Estatuto, dispõe que criança é aquela de até 12 anos incompletos e o adolescente aquele de 12 anos completos até 18 anos. 
Nesse viés, Nucci (2011) faz a seguinte assertiva:

\begin{abstract}
A tutela do direito penal, no campo dos crimes sexuais, deve ser absoluta, quando se tratar de crianças (menor de 12 anos), mas relativa ao cuidar do adolescente (maior de 12 anos). É viável debater a capacidade de consentimento de quem possua 12 ou 13 anos, no contexto do estupro de vulnerável. Havendo prova de plena capacidade de entendimento da relação sexual, não tendo ocorrido violência ou grave ameaça real, nem mesmo qualquer forma de pagamento, o fato pode ser atípico ou comportar desclassificação. (NUCCI, 2011, p. 928).
\end{abstract}

Cumpre destacar que alguns Tribunais ainda utilizam o fundamento de vulnerabilidade relativa em determinados casos de estupro de vulnerável, as quais fazem uso de uma interpretação contextual de cada caso in concreto, ignorando Lei 12.015/09 e a súmula 593 do STJ. Vejamos:

APELAÇÃO CRIMINAL ESTUPRO - RECURSO DA DEFESA VISANDO A ABSOLVIÇÃO - ACOLHIMENTO. Violência presumida. Caráter absoluto - Não ocorrência. Ofendida com 12 anos de idade que demonstra possuir discernimento dos atos praticados. Circunstâncias comprovadas pelas declarações da própria vítima e pela prova testemunhal. Tipo penal não configurado. Apelo provido, para absolver o réu. (TJSP, Apelação $\mathrm{n}^{\circ}$ 0006109-96.2009.8.26.0363, $1^{\text {a }}$ Câmara Criminal Extraordinária, Rel. Des. Luís Augusto de Sampaio Arruda, julgado em 19/05/2014). (BRASIL, 2014).

Ante o exposto, fica evidente que a discussão sobre a presunção absoluta de vulnerabilidade de menores de 14 anos está longe de se findar. Alguns Doutrinadores e Tribunais entendem que deveria ser relativa a vulnerabilidade entre os adolescentes de 12 e 14 anos, analisando-se cada caso concreto. Outros, seguem rigidamente o disposto em Lei, independente das circunstâncias no caso.

\title{
5 VALOR PROBATÓRIO DA PALAVRA DA VÍTIMA E SUAS FRAGILIDADES
}

Carvalho (2009), dispõe que no processo penal a prova é usada como instrumento para a formação do convencimento do Juiz sobre determinado fato delituoso. A finalidade dela é restaurar determinado fato presente no processo.

E conforme Capez (2013), o crime de estupro nem sempre deixa vestígios, como na tentativa, onde não chega a ocorrer a conjunção carnal, dificilmente restarão elementos no ofendido para periciar, e, mesmo que haja a consumação, os resquícios podem desaparecer com o tempo. 
Destaca-se a prova testemunhal, que é de suma importância, como sendo a existência de uma pessoa que é chamada em Juízo, sob juramento, para declarar a respeito do fato delituoso. Nesse sentido, Mittermaier (2008) define testemunha como aquela pessoa chamada a depor, conforme sua experiência individual, sobre a existência de um fato e sua natureza.

Segundo Capez (2017), quando se fala em crime de estupro, em especial de vulnerável, na maioria dos casos, pela própria natureza do delito, não deixa testemunhas ou vestígios, o que o torna "clandestino".

Certamente, a ausência de vestígios de materialidade e de testemunhas no caso, fica difícil a comprovação do ato ilegal. Porém, no que tange a produção de provas nos crimes sexuais contra vulneráveis, dada a peculiaridade dos envolvidos, a jurisprudência afirma que a palavra da vítima tem relevante valor probatório e muitas das vezes suficiente para condenar o acusado, quando coerente.

Assim, o Superior Tribunal de Justiça entende que nos casos de estupro de vulnerável, o depoimento da vítima é relevante, desde que coerente:

AGRAVO REGIMENTAL NO AGRAVO EM RECURSO ESPECIAL. ESTUPRO DE VULNERÁVEL. ABSOLVIÇÃO. IMPOSSIBILIDADE. SÚMULA 7/STJ. PALAVRA DA VÍTIMA. RELEVÂNCIA. VIOLAÇÃO DO ART. 156 DO CPP. NÃO OCORRÊNCIA. AGRAVO IMPROVIDO.1. A Corte de origem concluiu pela existência de prova apta a amparar o édito condenatório, de modo que a reversão do julgado demandaria incursão fático probatória, vedada no âmbito do recurso especial, nos termos da Súmula 7/STJ.2. É firme o entendimento do Superior Tribunal de Justiça de que, em crimes contra a liberdade sexual, praticados, em regra, de modo clandestino, a palavra da vítima possui especial relevância, notadamente quando corroborada por outros elementos probatórios. 3. Ausente violação do art. 156 do CPP na hipótese em que a condenação encontra respaldo nos elementos probatórios dos autos, não logrando a defesa êxito sua na desconstituição. Incidência da Súmula 83/STJ. 4. Agravo regimental improvido. (AgRg no AREsp 1493646/MG, Rel. Min. Nefi Cordeiro, Sexta Turma, Dje 24/10/2019). (BRASIL, 2019).

Desse modo, pode- se entender que a vítima de estupro de vulnerável, ao ser ouvida, terá uma palavra uma grande valoração probatória. Assumindo assim o STJ os riscos ao fundar-se apenas em palavras, visto que não são raros os casos de repercussão social, onde os acusados são condenados injustamente pelo crime. Deve-se ter um cuidado especial nesses crimes clandestinos, investir em várias consultas com psicólogos especializados, para averiguar se a palavra da vítima corrobora com os demais elementos, se existentes. 
Mesmo que haja vestígios, a comprovação da autoria e materialidade do fato podem estar comprometidas. Seja porque a vítima está sendo influenciada a dizer inverdades por seu guardião, por estar investida pela chamada falsas memórias ou pelo envolvimento/despreparo dos profissionais da psicologia.

\title{
5.1 Alienação Parental
}

$\mathrm{Na}$ atualidade, tem-se tornado corriqueiro o número de casos onde há falsas denúncias influenciadas pelo guardião da criança, principalmente em casos onde existe disputa de guarda ou quando um dos genitores quer se vingar do(a) ex-companheiro(a), nutrindo um sentimento de mágoa. Tal comportamento, segundo Buosi (2012) é denominado de Síndrome de Alienação Parental (SAP), criada pelo americano Richard Gardner e aderida ao nosso ordenamento jurídico, a qual foi instituída pela lei $12.318 / 10$.

A mesma afirma que:

[...] o inconformismo do cônjuge com a separação, a depressão, a insatisfação das condições econômicas advindas pelo fim do relacionamento, a necessidade de posse exclusiva sobre os filhos, a solidão a que se vê no presente ou o fato do ex-cônjuge manter a relação com o parceiro da relação extramatrimonial que adveio a separação são causas determinantes para que um dos cônjuges (geralmente o detentor da guarda) utilize-se da única "arma" que lhe resta para atingir e vingar-se de outro: os filhos do ex-casal. (BUOSI, 2012, p.57).

Para melhor vislumbrar, vejamos um caso real onde um pai foi condenado por estuprar seus próprios filhos, vítimas da Alienação Parental:

\begin{abstract}
Fato relevante para a justiça brasileira ocorreu com Atercino Ferreira de Lima Filho, que foi condenado a cumprir a pena de 27 anos de prisão, por ter abusado sexualmente de dois filhos menores, o menino com oito e a menina com sete. A delação criminal foi apresentada pela mãe das crianças, que as obrigou a depor e mentir para incriminar o pai. Ocorre que os filhos, após romperem o relacionamento com a genitora, manifestaram-se em sentido contrário, justificando que tinham sido coagidos por ela para incriminar o pai, já condenado definitivamente. Somente em sede de revisão criminal, por unanimidade, o TJ/SP reconheceu a inocência de Atercino. (JÚNIOR, 2018).
\end{abstract}

Dessa forma, percebe-se uma atuação psicopática da genitora, pois sujeitar o bem-estar de seu próprio filho e do adulto acusado em prol de seu próprio interesse, é algo muito grave. Temos aqui, a criança, suposta vítima que irá passar por várias avaliações, na qual toda a situação pode lhe causar sequelas psíquicas duradouras. E o 
pai, acusado injustamente, onde terá de carregar esse fardo da acusação de estupro do próprio filho, toda pressão social, pelo resto da sua vida. Pois esse tipo de acusação mesmo que depois provada sua inocência, se perpetua.

Nesse viés, Amendola (2013) afirma que

[...] sustentar a palavra da criança como única verdade, nesses casos, pode ser o equivalente a desconsiderar sua condição de sujeito, mediante à possibilidade de a criança estar assujeitada ao pensamento materno, por meio de alinhamentos ou fortes vínculos estabelecidos, tornando-se objeto da mãe. (AMENDOLA, 2013, p. 177).

Ademais, a alienação parental está ligada às falsas memórias, porém aqui esta ocorre por meio da ação do alienador, a qual implementa algo que nunca ocorreu. Buosi (2012) alerta que, segundo publicações norte-americanas, cerca de $30 \%$ dos alegados incestos são falsos, número esse também aplicado aos casos registrados no Brasil.

Com isso, além de investigar o crime de estupro de menor de 14 anos, deve se atentar ao histórico da relação dos genitores, para que assim possa reduzir as chances de falsas alegações por meio da Alienação Parental. Não se trata de desvalorizar e subestimar todo o depoimento da vítima, mas de destacar a necessidade de considerar o contexto completo e tomar cautelas para identificá-lo além do que é informado voluntariamente.

\subsection{Falsas memórias}

Quando se fala a palavra memória, associa-se a algo do passado e as experiências individuais de cada indivíduo. Conforme pressupõe Izquierdo (2004): “A memória humana é caracterizada pela capacidade dos seres humanos de adquirir, conservar e evocar informações através de dispositivos neurobiológicos e da interação social"' (IZQUIERDO, 2004, p.15).

$\mathrm{Na}$ esfera jurídica a memória é muito importante, sendo relevante para a determinação dos fatos e da investigação. No entanto, existe um fenômeno chamado de falsas memórias que afeta o depoimento de testemunhas, vítimas e inclusive o réu.

De acordo com Stein (2010), falsas memórias consistem em recordações de situações que nunca aconteceram, porém a pessoa acredita que aconteceu. No âmbito internacional esse fenômeno é algo de várias pesquisas, em busca de explicações, haja vista que existem acontecimentos delituosos envolvendo crianças vítimas de violências 
físicas e sexuais. Esses depoimentos fragilizados pelas falsas memórias podem ser decisivos na vida da vítima e do acusado.

Em 1994, um caso teve grande repercussão em nosso país, ocorrido em São Paulo e popularmente conhecido como "Caso Escola Base". Essa foi uma das maiores injustiças ocorridas no Brasil, tanto pelos policiais quanto pela imprensa, que não hesitaram em massacrar brutalmente os acusados. Ficou marcada como um dos julgamentos mais históricos de nosso país, mesmo tendo o judiciário aferido a existência de falsas memórias e os acusados todos absolvidos, isso porque nenhuma indenização milionária jamais será capaz de cicatrizar as sequelas e ataques que os mesmos sofreram.

Em síntese, segundo Ribeiro (2003), tudo começou quando uma das crianças, suposta vítima, sentou na barriga de sua mãe e perguntou se era assim que os homens faziam com as mulheres. Após o "interrogatório" feito pela mãe, ela afirmou que seu filho tinha assistido a uma fita pornográfica na casa de um coleguinha, que por sinal era muito semelhante a um motel e que eram levados de Kombi até o local. O fato foi levado à Delegacia e as crianças ao IML, pois apresentavam assaduras, na qual obteve um mandado de busca e apreensão. Porém, nada foi encontrado na escola e nem na casa dos suspeitos. Não satisfeitas, as mães foram à imprensa, que não hesitaram em divulgar informações, perseguir e redigir notícias acusatórias, sem nenhuma prova concreta. Por fim, tudo não passou de um terrível engano, sendo os acusados inocentes e as crianças vítimas de falsas memórias sugeridas, ou seja, nada era real.

Diante da análise desse fenômeno e a relevância da palavra da vítima como prova no crime de estupro de vulnerável, nem mesmo a memória é confiável. Vale ressaltar que este fenômeno ocorre inconscientemente, ou seja, o indivíduo não sabe que sua memória está afetada, seja internamente ou externamente. É algo que ocorre involuntariamente. Diferente da mentira, onde o indivíduo tem plena consciência da informação relatada e da sua inverdade.

\subsection{Técnica adequada de entrevista}

Outro cuidado indispensável é na formulação de questionamentos feitos pelo psicólogo, direcionados às vítimas de abusos sexuais, devendo utilizar a forma menos danosa e o mais célere possível. 
Ao efetuar a entrevista com a vítima, o profissional da psicologia deve "criar um ambiente facilitador que permita à criança revelar o abuso sexual a partir da produção discursiva, lúdica e gráfica, sem desenvolver sentimento de culpa ou vergonha". (AMENDOLA, 2013, p. 179).

A maneira de questionar a criança ou adolescente é um aspecto preponderante, levando em consideração as várias técnicas de indução a resposta. O ideal é não fazer perguntas sugestivas a respostas e avaliar os comportamentos da suposta vítima, para assim produzir o laudo a ser usado em Juízo.

Um caso polêmico aconteceu em São Paulo, na qual o funcionário de uma escola está preso, acusado de abusar de meninas de 3 anos. Uma delas fez o reconhecimento presencial na delegacia e as outras duas por meio de foto, segue um trecho da matéria:

\begin{abstract}
Ao ser indagada pelo delegado, a criança reconheceu o acusado, Antônio : "O delegado perguntou: "Quem é o tio Antônio malvado? "De imediato, ela apontou para Antônio, que era o segundo da esquerda para a direita e disse: "Bate nele. Bate no bumbum dele". O repórter foi até o presídio onde está o acusado para questioná-lo sobre o reconhecimento de uma das meninas, e ele afirma: "Na semana de Páscoa teve uma peça de teatro ao qual eu participei e eu fazia o papel de um menino travesso, de menino malvado. Depois que houve essa peça, eu fiquei conhecido na escola, entre eles, como o tio malvado. Eles saíam do carro: "Olha o tio malvado. Mamãe, olha o tio malvado. (G1. GLOBO, 2014).
\end{abstract}

Sobre o caso, destaca-se a falta de profissional especializado para acompanhar o reconhecimento e o depoimento das crianças, a psicóloga Lúcia Cavalcanti Williams professora titular da Universidade Federal de São Carlos, referência no estudo e prevenção à violência na escola, destaca "Do ponto de vista da psicologia esse procedimento é questionável. Você precisa ser capacitado para entrevistar a criança e coletar essa fala de maneira cristalina, sem influenciar, sem colocar palavras na boca dessa criança”. (G1. GLOBO, 2014).

Em análise, fica clara que a pergunta feita pelo delegado foi sugestiva, haja vista que segundo o acusado, ele havia feito um papel teatral na escola e titulado pelas crianças como "tio malvado". Demonstrando a falta de um profissional especialista e qualificado para acompanhar o depoimento, bem como na elaboração das perguntas.

Ainda, ressalta-se o envolvimento do psicólogo no caso de estupro, sendo este responsável por colher as informações do depoimento da vítima e após, apresentar seu laudo ao Juízo. De acordo com Thouvenin (1997): “Assim, a palavra da criança, transformada e modulada pela interpretação do adulto que lhe dá assistência, não raro, 
tende a expressar as impressões pessoais desse adulto, que não hesita em condenar o autor do suposto abuso". (THOUVENIN, 1997, p. 98).

Em pesquisa, Amendola (2013) constatou que grande parte dos psicólogos não possuem capacitação ou treinamento específico para avaliar casos de abuso sexual. Ainda, a mesma afirma que "os profissionais, apesar dos esforços empreendidos nas últimas décadas, não são capacitados para tratar das questões da violência, havendo grande ausência sobre este tema nos currículos superiores".

Percebe-se duas situações que podem prejudicar na busca pela verdade real. A primeira é a interpretação pessoal do psicólogo ao entrevistar a vítima. A segunda é o despreparo do profissional para lidar com tais casos práticos, pois o ensino superior não os prepara devidamente.

Sobre o assunto, o Conselho Nacional de Justiça - CNJ publicou a Resolução 299/19, que estabelece que crianças e adolescentes, sejam vítimas ou testemunhas de violência, tenham seus depoimentos colhidos em um espaço adequado e por profissionais com treinamento específico, para assim preservar a integridade física e emocional, devendo os tribunais de todo o país apresentar estudos para a criação de varas especializadas. (MIGALHAS, 2019).

A Resolução supracitada trouxe determinações de muita relevância para nosso ordenamento jurídico, porém mesmo com os tribunais oferecendo um espaço e profissional adequado para colher o depoimento, deve-se ter atenção a todas as circunstâncias do crime.

\section{CONSIDERAÇÕES FINAIS}

Cumprindo com os preceitos constitucionais e visando a proteção da criança e do adolescente o legislador apresentou um novo instituto, tipificado como de estupro de vulnerável e incluído pela Lei 12.015/09, estabelecendo um critério etário e biológico para o alcance dos sujeitos passivos do delito.

No que tange a presunção de vulnerabilidade ser absoluta, um dos rigores decorrentes da lei, o legislador tinha por objetivo colocar um fim na discussão, porém muitos juristas e magistrados não concordam e entendem ser relativa, permanecendo as discussões no mundo jurídico e uma série de decisões contrárias a legislação atual. 
Vale ressaltar que quando valora-se a palavra da vítima, principalmente quando criança, sem observar as fragilidades que esta possui, cria-se brechas para a condenação de um inocente. Haja vista as influências que a vítima pode estar exposta, sendo usada como objeto de vingança ou por inconscientemente sua memória estar em desacordo com a realidade.

Evidentemente a palavra da vítima será analisada corroborando com as demais provas nos autos, o que geralmente é apenas o laudo psicológico em razão de ser um crime clandestino, onde não há testemunhas, o que o torna falho, uma vez que o laudo psicológico não é completamente seguro, tendo em vista o despreparo para lidar com tais casos.

A ideia não é desqualificar, desacreditar ou ignorar o depoimento da criança ou adolescente, mas alertar nos cuidados que devem ser tomados em sua oitiva, pois sua palavra tem grande peso na decisão tomada pelo magistrado. O objetivo não é defender a vítima e nem o acusado, mas sim um alcance efetivo da prestação jurisdicional e da busca pela verdade real.

Infelizmente, erros humanos acontecem ou até mesmo uma falha da lei, mas crimes como estes, na qual será decidido sobre o futuro do acusado, as possibilidades de erros devem ser mínimas. Tem que proteger o vulnerável, mas sem deixar margens para condenar um inocente.

Diante disso, o estudo demonstra o quão delicado é a palavra da vítima, de tal forma a ser complexo, porém proporcional a delicadeza que o crime traz, afinal é a violação sexual de um vulnerável. Um passo foi dado, com a resolução 299/19 do Conselho Nacional de Justiça, que determina a presença de um profissional especializado em um ambiente adequado, para assim lidarem com as situações como as apresentadas e produzirem uma prova de qualidade. Pois, uma condenação baseada apenas na palavra da vítima, exige uma segurança extrema de que está certo sobre a autoria e materialidade do delito. E caso haja dúvidas, aplicar o princípio "in dubio pro reo".

\section{REFERÊNCIAS}

AMENDOLA, Marcia Ferreira. Crianças no labirinto das acusações: falsas alegações de abuso sexual. 1. ed. Curitiba: Juruá, 2013.

BITENCOURT, Cesar Roberto. Tratado de Direito Penal. 11. ed. São Paulo: Saraiva, 2017. v.4. 
BRASIL. Lei $\mathbf{n}^{\mathbf{0}} \mathbf{1 2 . 0 1 5}$ de 7 de agosto de 2009 - Exposição de motivos.Disponível em: https://www2.camara.leg.br/legin/fed/lei/2009/lei-12015-7-agosto-2009-590268exposicaodemotivos-149280-pl.html. Acesso em: 30 de novembro de 2019.

. SUPERIOR TRIBUNAL FEDERAL. Agravo Regimental no Habeas Corpus n. 130.297. Rel. Min. Rosa Weber. Disponível em:

http://stf.jus.br/portal/jurisprudencia/listarJurisprudencia.asp?s1=\%28PRESUNCAO+D E+VULNERAVEL\%29\&base=baseAcordaos\&url=http://tinyurl.com/y3f4ph9c. Acesso em: 01 de novembro de 2019.

. SUPERIOR TRIBUNAL DE JUSTIÇA. Agravo Regimental no Agravo em Recurso Especial. n. 1493646. Rel. Min. Nefi Cordeiro. Disponível em: https://scon.stj.jus.br/SCON/jurisprudencia/toc.jsp. Acesso em: 12 de novembro de 2019.

. Tribunal de Justiça de São Paulo. Apelação Criminal n. 000610996.2009.8.26.0363. Rel. Des. Luis Augusto de Sampaio Arruda. Disponível em: https://esaj.tjsp.jus.br/cjsg/resultadoCompleta.do. Acesso em 12/11/2019.

BUOSI, Caroline de Cássia Francisco. Alienação parental: uma interface do direito e da psicologia. Curitiba: Juruá, 2012.

CAMPOS, Pedro Franco, de. et al. Direito penal aplicado: parte especial do código penal. 5. ed. São Paulo: Saraiva, 2013.

CAPEZ, Fernando. Curso de direito penal. 9. ed. São Paulo: Saraiva, 2017, v.3.

2013. v.

Curso de direito penal: parte especial. 11. ed. São Paulo: Saraiva,

CARValho, Djalma Eutímio. Curso de Processo Penal. 2. ed. Rio de Janeiro: Editora Forense, 2009.

FRANCO, Alberto Silva. Crimes Hediondos/ Alberto Silva Franco. 7. ed. rev., atual. E ampl. São Paulo : Editora Revista dos Tribunais, 2011.

GARBIN, Aphonso Vinicius. Estupro de vulnerável, a palavra da vítima e os riscos da condenação. Disponível em: https://canalcienciascriminais.com.br/estupro-devulneravel-a-palavra-da-vitima-e-os-riscos-da-condenacao/. Publicado em 22/04/2016. Acesso em: 11 de novembro de 2019.

GRECO, Rogério. Curso de direito penal: parte especial. 14. ed. Niterói: Impetus, 2017. v.3.

Código penal comentado. Rio de Janeiro: Editora Impetus, 2013.

G1, Globo. Acusado de Estupro de crianças diz que é inocente. Disponível em: http://g1.globo.com/fantastico/noticia/2014/11/acusado-de-estupro-de-criancas-diz-quee-inocente.html. Publicado em 23/11/2014. Acesso em: 20/03/2020.

IZQUIERDO, Iván. Questões sobre Memórias. São Leopoldo: Editora Unisinos, 2004. JÚNIOR, Eudes Quintino de Oliveira. O depoimento infantil nos crimes sexuais. Disponível em: https://www.migalhas.com.br/dePeso/16,MI275982,31047O+depoimento+infantil+nos +crimes+sexuais. Publicado 11/03/2018. Acesso em: 12 de novembro de 2019.

MASSON, Cleber. Direito Penal Esquematizado. 6. ed. São Paulo: Método, 2016. v.3. 
MIGALHAS. O CNJ publica novas regras para depoimento especial de crianças e adolescentes vítimas de violência. Publicado 12/12/2019. Disponível em: https://www.migalhas.com.br/quentes/316950/cnj-publica-novas-regras-paradepoimento-especial-de-criancas-e-adolescentes-vitimas-de-violencia. Acesso em: $15 / 04 / 2020$.

MITTERMAIER, C. J. A. Tratado da prova em matéria criminal. Campinas: Bookseller, 2008.

NUCCI, Guilherme de Souza. Crimes contra a dignidade sexual. 2. ed. São Paulo: Editora Revista do Tribunais, 2011.

Crimes contra a dignidade sexual: de acordo com a Lei 12.015/2009/Guilherme de Souza Nucci. 2. ed. re., atual. E ampl. São Paulo: Editora Revista dos Tribunais, 2010.

RIBAS, Adrieli Ferreira. Valor Probante da Palavra da Vítima no crime de estupro de vulnerável e o risco da condenação injusta. 8. ed. In: Revista Aporia Jurídica (online). Revista Jurídica do Curso de Direito da Faculdade CESCAGE. v.1.

RIBEIRO, Alex. Caso Escola Base: os abusos da imprensa. São Paulo: Editora Ática, 2003.

ROCHA, Francisco de Assis do Rêgo Monteiro. Curso de direito processual penal. Rio de Janeiro: Forense, 1999.

STEIN, Lilian Milnitsky. Falsas memórias: Fundamentos científicos e suas aplicações clínicas e jurídicas. Porto Alegre: Artmed, 2010.

THOUVENIN, C. A palavra da criança: do íntimo social. In: GABEL, M. (org.). Crianças Vítimas de abuso sexual. São Paulo: Summus, 1997. 